\title{
PARALARYNGEAL ABSCESS PRESENTED WITH ACUTE BREATHLESSNESS AND HOARSENESS OF VOICE: A RARE ENTITY
}

\author{
Vinayaka U. S1 ${ }^{1}$ Ajaml Shaad C. M², Vijayalakshmi S³, Sheethal Rai ${ }^{4}$
}

\section{HOW TO CITE THIS ARTICLE:}

Vinayaka U. S, Ajaml Shaad C. M, Vijayalakshmi S, Sheethal Rai. "Paralaryngeal Abscess Presented with Acute Breathlessness and Hoarseness of Voice: A Rare Entity". Journal of Evolution of Medical and Dental Sciences 2014; Vol. 3, Issue 31, July 31; Page: 8620-8623, DOI: 10.14260/jemds/2014/3096

\begin{abstract}
Parapharyngeal abscess are commonly encountered in clinical practice, But paralaryngeal abscess is a rare entity. Paralaryngeal abscesses are known to develop in patients with predisposing factors like immunocompromised status and foreign body impactions. The patients commonly present with fever \& constitutional symptoms in addition to respiratory symptoms. We report an unusual case of acute severe breathlessness with hoarseness of voice of one hour duration without any predisposing factors or any constitutional symptoms, who was later diagnosed to have paralaryngeal abscess after investigations.
\end{abstract}

KEYWORDS: Paralaryngeal abscess, hoarseness of voice, Computed Tomography.

INTRODUCTION: There is a wide variety of infectious and inflammatory disorders of the head and neck that may manifest in emergency room. ${ }^{1}$ Computed tomography (CT) is the first-line imaging modality in the acute setting, however magnetic resonance (MR) imaging plays an important secondary role. Magnetic resonance imaging (MRI) is strongly recommended today to use in children to diminish radiation. MRI is superior in imaging of soft tissue masses compared to CT. ${ }^{1}$

The presenting features of infections of the retropharyngeal and parapharyngeal space are highly variable and illustrate the difficulty in making a diagnosis based on symptoms alone. The most common symptoms at presentation based on the study conducted by G Grisaru-Soen, et al were fever $(70 \%)$ and neck pain (62\%), followed by dysphagia (51\%), palpable neck mass(46\%) and sore throat $(31 \%)^{2}$

Breathlessness or dyspnea is an unpleasant sensation of uncomfortable, rapid or difficult breathing. It may have sudden onset as acute breathlessness or gradually develop over a period of time as chronic breathlessness. ${ }^{2}$ Acute breathlessness may be due to diseases of cardiac, pulmonary, upper airway or psychiatric and could be physiological also. Hoarseness of voice is a condition where there is abnormal change in voice. ${ }^{3}$ Any disease involving the larynx may cause change in the voice.

The combination of acute breathlessness and hoarseness of voice is medical emergency indicating obstruction of upper airway at the level of larynx. The common causes of hoarseness of voice and acute breathlessness are laryngitis, anaphylaxis, angioneurotic edema, laryngeal malignancy, external compression by bleed within thyroid nodule, inflammatory collection around larynx or pharynx etc.

Deep seated neck abscess is one of the causes of upper airway compression resulting in breathlessness \& change in voice. Even though the advent of the antibiotics has dramatically decreased the incidence of deep neck infection, they remain prevalent especially in immunecompromised patient. ${ }^{3}$ Early and aggressive management of parapharyngeal abscess can prevent major complications such as mediastinitis, vascular complications, septicemia, etc. ${ }^{3}$ 
Retropharyngeal and parapharyngeal abscesses are rare but associated with significant morbidity and potential mortality.

CASE REPORT: We report an unusual case of acute severe breathlessness with hoarseness of voice for one hour duration without any predisposing factors or any constitutional symptoms in a 31 year old female patient who presented to emergency department. The clinical examination of neck \& laboratory examination were unremarkable and on CECT evaluation of neck revealed paralaryngeal abscess. Complete Surgical drainage of the abscess relieved the symptoms of the patient.

Even though parapharyngeal abscess is a common entity, paralaryngeal abscess causing breathlessness and hoarseness of voice is a rare entity, and not reported much in the literature.

CT is the first-line imaging modality for infectious and inflammatory conditions of the head and neck in the emergency setting. ${ }^{1}$ An understanding of less common but potentially life-threatening conditions also is important to ensure prompt diagnosis and optimal treatment. ${ }^{1}$

In our case, CECT neck was done which showed an ill-defined collection approximately measuring $28 \times 13 \mathrm{~mm}$ in the left para laryngeal region (Figure.1 \& Figure.2) with retro laryngeal extension causing compression of glottis which was indirectly causing hoarseness of the voice and breathlessness in the patient.

On the basis of the imaging findings, diagnosis of paralaryngeal abscess was made which is an uncommon location of abscess in neck; later patient was operated and relieved of symptoms after surgical drainage of abscess. ${ }^{4}$

DISCUSSION: Contrast-enhanced CT scan (CECT) is the gold standard in the evaluation of deep neck infections. $^{3}$ CT scans provides valuable information for the site and the extent of infection ${ }^{3}$ Retropharyngeal space collection include an evaluation of multiplanar imaging for four characteristics: distribution of fluid, configuration and mass effect, presence or absence of a thick enhancing wall, and ancillary findings. ${ }^{4}$

Paralaryngeal abscess can occur as a complication of laryngitis, but it is most commonly associated with immuno-compramised patients or patients with poor general health and in perticular in patients after trauma or injury through ingestion of foreign bodies. In advanced cases it is associated with extra laryngeal inflamatory reaction effecting the adjacent lymphnodes in that region, in addition to the compression of the airway with stridor on inspiration.

The unique features in our patient include presentation of breathlesness and hoarseness of voice without any prior history or predisposing factor which was diagnosed as paralaryngeal abscess which is a rare entity, eventhough parapharyngeal abscess is common.

CONCLUSION: CT is a useful modality for assessing the extent of laryngeal lesions and for evaluating complications. It may also be useful for differentiating this condition from other supraglottic diseases, for the planning of treatment, and for evaluating the results of therapy.

\section{REFERENCES:}

1. Capps EF, Kinsella JJ, Gupta M, Bhatki AM, Opatowsky MJ. Emergency imaging assessment of acute, non-traumatic conditions of the head and neck. Radiographics. 2010 Sep; 30 (5): 133552. 


\section{CASE REPORT}

2. G. Grisaru-Soen et al, Retropharyngeal and parapharyngeal abscess in children Epidemiology, clinical features and treatment. Int J Pediatr Otorhinolaryngol.2010; 74: 1016-20.

3. Gani AN, Abdullah A, Hazim MYS, Rozman Z. Parapharyngeal Abscess in Immunocompromised Patients. Med \& Health 2007; 2 (2): 158-163.

4. Hoang et al. Multiplanar CT and MRI of Collections in the Retropharyngeal Space: Is It an Abscess? AJR 2011; 196:W426-W432.
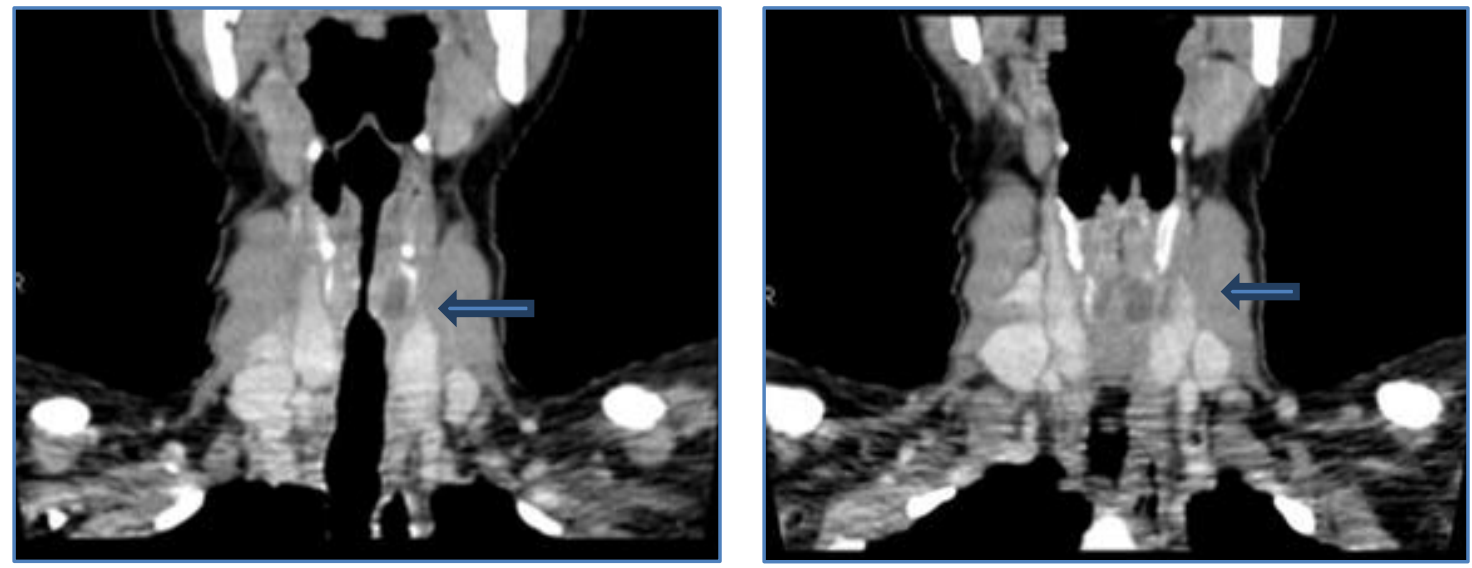

Fig 1: Coronal CECT-NECK showing ill-defined collection in the left paralaryngeal region with retro-laryngeal extension
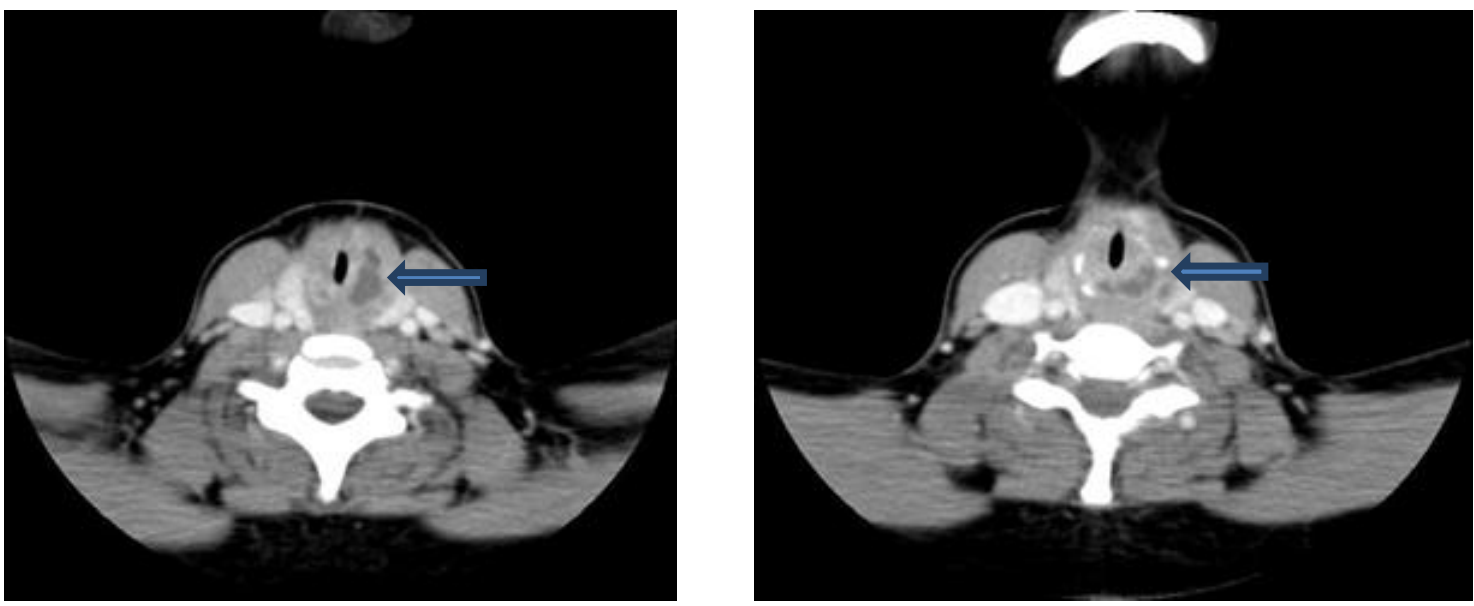

Fig. 2: Axial CECT-NECK-showing ill-defined collection in the left paralaryngeal region with retro laryngeal extension causing compression of the glottis 


\section{CASE REPORT}

\section{AUTHORS:}

1. Vinayaka U.S.

2. Ajaml Shaad C. M.

3. Vijayalakshmi S.

4. Sheethal Rai

\section{PARTICULARS OF CONTRIBUTORS:}

1. Assistant Professor, Department of Radiology, Yenepoya Medical College \& Hospital, Deralakatte, Mangalore.

2. Post Graduate, Department of Radiology, Yenepoya Medical College \& Hospital, Deralakatte, Mangalore.

3. Associate Professor, Department of ENT, Yenepoya Medical College \& Hospital, Deralakatte, Mangalore.
4. Assistant Professor, Department of ENT, Yenepoya Medical College \& Hospital, Deralakatte, Mangalore.

\section{NAME ADDRESS EMAIL ID OF THE CORRESPONDING AUTHOR:}

Dr. Vinayaka U.S,

Department of Radiology,

Yenepoya Medical College \& Hospital,

Deralakatte,

Mangalore-575003.

Email:drvinayaka@yahoo.com

Date of Submission: 12/07/2014.

Date of Peer Review: 13/07/2014.

Date of Acceptance: 22/07/2014.

Date of Publishing: 30/07/2014. 